\title{
A new algorithm for computation of horizontal-well pressure in Laplace domain
}

\author{
Mingtao $\mathrm{Wu}^{1,2}$, Wanjing Luo ${ }^{1,2 *}$, Xiaodong Wang ${ }^{1,2}$ \\ ${ }^{1}$ School of Energy Resources, China University of Geosciences, Beijing 100083, P. R. China \\ ${ }^{2}$ Beijng Key Laboratory of Unconventional Natural Gas Geological Evaluation and Development Engineering, \\ China University of Geosciences, Beijing 10083, P. R. China
}

(Received July 22, 2018; revised August 10, 2018; accepted August 11, 2018; available online August 18, 2018)

\section{Citation:}

Wu, M., Luo, W., Wang, X. A new algorithm for computation of horizontal-well pressure in Laplace domain. Advances in Geo-Energy Research, 2018, 2(4): 393-403, doi: 10.26804/ager.2018.04.04.

Corresponding author:

*E-mail: luowanjing@cugb.edu.cn

Keywords:

Computation algorithm

horizontal well with pressure drop

varying conductivity

Laplace domain

\begin{abstract}
:
The effect of wellbore pressure drop on horizontal well pressure response is relatively important when flow velocity is high or the surface of horizontal wellbore is rough. The objective of this study is to develop a stable and robust algorithm in Laplace domain to analyze horizontal-well pressure with pressure drop along the wellbore. Based on the novel definitions of horizontal well permeability and conductivity, the equation of fluid flow along a horizontal wellbore with pressure drop has the same form as that of fluid flow in a varying-conductivity fracture. A new dimension transformation has been used to change the varying-conductivity model into a constant-conductivity model, and then an iterative procedure has been introduced to obtain the pressure. This algorithm is developed in Laplace domain and eliminates the need for computations in the time domain. Besides, the skin effect and wellbore storage is easily to be taken into consideration.
\end{abstract}

\section{Introduction}

As an efficient stimulation technique, horizontal-well completion plays an increasingly significant role in conventional and unconventional resources exploitation to improve well productivity and recovery (Abbasy et al., 2008; Birtt et al., 2010; Wang et al., 2017; Liu et al., 2018; Luo et al., 2018b). Horizontal well can transform the radial flow into linear flow, which can enhance availability of the reservoir energy during production and enlarge well drainage area (Wang et al., 2014; Luo et al., 2018c).

It is a common practice to use transient pressure test to evaluate reservoir and well parameters. There are a lot of studies have been done to develop the mathematical models to obtain horizontal-well transient pressure and productivity (Giger et al., 1984; Goode and Thambynayagam, 1987; Joshi, 1988; Mutalik, 1988; Babu and Odeh, 1989; Al-Haddad and Crafton, 1991; Goode, 1991; Cho, 2003; Adesina et al., 2007; Wang and Economides, 2009; Luo et al., 2014; Luo and Tang, 2015; Chen et al., 2017; Li et al., 2017). These models do not take the pressure drop due to roughness along the surface of the horizontal wellbore into account. Horizontal wells are usually idealized as infinite-conductivity wellbores (Daviau et al., 1985; Clonts and Ramey, 1986), which is reasonable while the magnitude of the pressure drop in the wellbore is negligibly small compared with that in the reservoir.

However, frictional and accelerational pressure drop is dominant for the long horizontal well with high production rate. Thus, ignoring the pressure drop may lead to unrealistic results. Many papers have been reported to study the effect of pressure drop on horizontal-well pressure responses and productivity performances. Dikken (1990) was the first to investigate the effect of pressure drop in the horizontal well on the production performance. His study demonstrated the fact that the pressure drop in a horizontal wellbore may be significant under certain conditions. However, Dikken assumed that productivity index of flow from the reservoir into the horizontal wellbore was constant along the wellbore. Sarica et al. (1994) extended this model to single-phase gas flow and studied the effect of wellbore hydraulics on transient pressure response and productivity of horizontal wells in gas reservoirs. Novy (1995) improved the model proposed by Dikken (1990) 


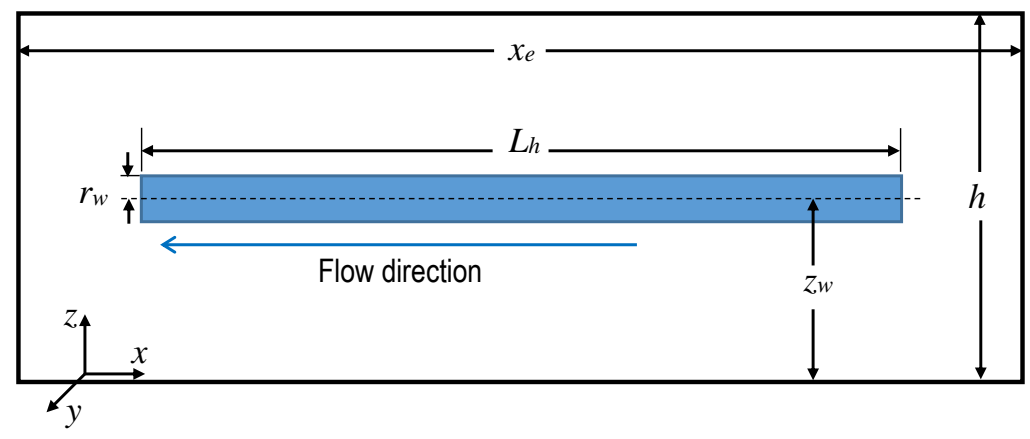

Fig. 1. Schematic of a horizontal-well-reservoir.

and provided criteria for the selection of reasonable horizontal length. Rested on the assumptions of steady-state flow in the reservoir and constant productivity index per unit of wellbore length, Dikken's correlation overestimates the effect of the friction with rough wall (Ozkan et al., 1995). These approximate models do not rigorously couple the wellbore and reservoir, which may lead to unrealistic conclusion on the effect of wellbore hydraulics. Ozkan et al. $(1995,1999)$ presented a comprehensive model that couples wellbore and reservoir hydraulics for the single-phase flow of a slightly compressible liquid. Ozkan et al.'s method is a more rigorous mathematical model which can account for different flow regimes (laminar and turbulent) and friction loss. Hill and Zhu (2006) showed how the relative importance of the pressure drop in the wellbore compared with in the reservoir and developed dimensionless groups to calculate the pressure drop in the wellbore. Recently, Yue et al. (2014) have developed a method for the optimization of perforation parameters considering pressure drop along horizontal wellbore. Chen et al. (2017) proposed a new model for pressure transient analysis in multiple-fractured horizontal well with consideration of pressure drop along the wellbore. Luo et al. (2018a) developed a semi-analytical mode to calculate the productivity index of a horizontal well with pressure drop along the wellbore. However, the pressure analysis method considering pressure drop due to turbulence in Laplace domain has not been reported.

As stated above, these models are proposed in time domain and computed with time and space discretization. In fact, the Laplace solutions are most popular in engineering calculation due to its convenience incorporating into the effect of skin factor and storage in wellbore and less cost of computation without time discretization. In this paper, we are attempting to develop a new algorithm in the Laplace domain for transient pressure analysis of horizontal well with respect to both laminar and turbulent flow in the wellbore. Also, the effects of wellbore storage and skin damage can also be incorporated in the new method, since all solutions are formulated in the Laplace domain.

\section{Physical model and assumptions}

In this study, we use the physical model proposed by Ozkan et al. (1995, 1999). The details of the physical model are elaborated as follows (Fig. 1):

(1) No-flow boundary condition is applied in the lateral direction ( $x$ and $y$ direction) and impermeable at the top $(z$ $=0)$ and bottom $(z=h)$ boundaries. It is homogenous with porosity $(\varphi)$ and permeability $(k)$.

(2) The flow in the reservoir is assumed to be single phase, isothermal, slightly compressible fluid with compressibility $(c)$, viscosity $(\mu)$ and density $(\rho)$.

(3) The horizontal wellbore extends, horizontally, in the $x$ direction and is located at elevation $\left(z_{w}\right)$ from the bottom boundary of the reservoir. The wellbore is of length $\left(L_{h}\right)$, radius $\left(r_{w}\right)$, and roughness $(\varepsilon)$ on its surface.

(4) The well is produced at the heel under constant rate $(q)$, while no flow is assumed across the toe of the well. The flow from the reservoir into wellbore is assumed to be continuous along the well length at a rate strength $\tilde{q}_{h}(x, t)$, which yields:

$$
\tilde{q}_{h}(x, t)=-\frac{\partial q_{h c}}{\partial x}
$$

where $q_{h c}(x, t)$ is flow within the wellbore. It is assumed to be 1-Dimensionel steady flow in the wellbore.

\section{Definitions}

For the sake of simplicity, the dimensionless variables are presented in Appendix A.

The Reynolds number is defined as:

$$
N_{R e}(x)=C_{R e} \frac{\rho \cdot q_{h} c(x)}{\mu r_{w}}
$$

with:

$$
C_{R e}=6.157 \times 10^{-2}
$$

In this study, the flow regime in the wellbore may be laminar, transitional or turbulent, depending on the value of Reynolds number. Furthermore, the fanning friction factor can be calculated based on Colebrook equation (Colebrook et al., 1939) as following:

$$
f(x)=\frac{1}{\left[1.14-2 \log \left(\frac{\varepsilon}{d}+\frac{21.25}{N_{R e}(x)^{0.9}}\right)\right]^{2}}
$$


We define horizontal-well permeability, $k_{h}(x)$, as:

$$
k_{h}(x)=1.88227 \times 10^{14} \times\left(\frac{r_{w}^{2}}{f(x) N_{R e}(x)}\right)
$$

According to Ozkan et al.'s definition for equivalentwellbore permeability:

$$
k_{w}=1.17642 \times 10^{13} \cdot r_{w}^{2}
$$

Eq. (5) can be written into:

$$
k_{h}(x)=k_{w} \times\left(\frac{16}{f(x) N_{R e}(x)}\right)
$$

The horizontal-well conductivity can also be defined as:

$$
C_{h D}(x)=\frac{k_{h}(x) A_{c}}{k h L_{r e f}}=C_{h D} \times\left(\frac{16}{f(x) N_{R e}(x)}\right)
$$

where, $C_{h D}$ is a constant defined by Ozkan et al. (1995 and 1999).

$$
C_{h D}=\frac{k_{w} A_{c}}{k h L_{r e f}}
$$

$A_{c}$ in Eqs. (8) and (9) denotes cross-sectional area of wellbore.

Note that the horizontal-well permeability, $k_{h}(x)$, and horizontal-well conductivity, $C_{h D}(x)$, are new variables defined in this study. Although they are analogous to Ozkan et al.'s definition in form, they are not CONSTANT but changing spatially.

\section{Mathematical models}

Under the assumption of 1D steady state flow in a horizontal wellbore, we have:

$$
\frac{d p_{h}}{d x}=C_{E} \frac{\rho}{\pi^{2} r_{w}^{5}} \cdot f \cdot q_{h c}^{2}
$$

with:

$$
C_{E}=9.117 \times 10^{-13}
$$

Substituting Eq. (2) into Eq. (10) and implementing the dimensionless transform, we have:

$$
\begin{aligned}
& \frac{C_{R e} \times 2 \times \pi^{2} \times 141.2}{C_{E}} \frac{r_{w}^{2}}{f(x) N_{R e}(x)}\left(\frac{A_{c}}{k h L_{r e f}}\right) \frac{d p_{h D}}{d x_{D}} \\
& =-q_{h c D} \cdot 2 \pi \\
& \bar{p}_{w D}-\bar{p}_{h D i}=\left(\frac{2 \pi}{\hat{C}_{h D}}\right) \cdot\left[\xi_{D i} \cdot \sum_{j=1}^{N} \bar{q}_{h D j}-\frac{\left(\xi_{D i}-\xi_{D i-1 / 2}\right)^{2}}{2 \cdot \Delta \xi_{D i}} \cdot \bar{q}_{h D i}-\sum_{j=1}^{i-1}\left(\frac{\Delta \xi_{D j}}{2}+\xi_{D i}-\sum_{n=1}^{j} \Delta \xi_{D n}\right) \cdot \bar{q}_{h D j}\right]
\end{aligned}
$$

Substituting Eqs. (7) and (8) into Eq. (12), the following equation for horizontal well in dimensionless form is obtained:

$$
C_{h D}\left(x_{D}\right) \cdot \frac{d p_{h} D}{d x_{D}}=-2 \pi \cdot q_{h c D}
$$

with boundary conditions:

$$
\left(\frac{d p_{h D}}{d x_{D}}\right)_{x_{D}=0}=-\left(\frac{2 \pi}{C_{h D}}\right), 0 \leq x_{D} \leq 2
$$

$$
\left(\frac{d p_{h D}}{d x_{D}}\right)_{x_{D}=2}=0
$$

Note that Eq. (13) has the same form as the one for varying-conductivity fracture proposed by Luo and Tang (2015).

\section{Semi-analytical Solution}

\subsection{Dimension transformation}

We firstly define a dimension transformation as follow:

$$
\xi_{D}=\xi_{D}\left(x_{D}\right)=\hat{C}_{h D} \cdot \int_{0}^{x_{D}} \frac{d x_{D}}{C_{h D}\left(x_{D}\right)}
$$

where:

$$
\hat{C}_{h D}=\frac{1}{\int_{0}^{2} \frac{d x_{D}}{C_{h D}\left(x_{D}\right)}}, x_{D} \in[0,2]
$$

Note that $\hat{C}_{h D}$ is CONSTANT.

Substituting Eq. (16) into Eq. (13) and integrating Eq. (13) with the boundary conditions, the solution can be expressed as in Laplace domain:

$$
\begin{gathered}
\bar{p}_{w D}-\bar{p}_{h D}\left(\xi_{D}\right) \\
=\left(\frac{2 \pi}{\hat{C}_{h D}}\right) \cdot\left(\xi_{D}-\int_{0}^{\xi_{D}} \int_{0}^{u_{D}} \overline{\tilde{q}}\left(v_{D}\right) d v_{D} d u_{D}\right)
\end{gathered}
$$

The overline "-" indicates variables in Laplace domain. It is worthy to note that Eq. (18) has the same form as the discretization equation of a vertical fracture (Ozkan and Raghavan, 1991; Luo and Tang, 2015). Based on our work, we build bridges between the horizontal well and vertical fracture. Thus, the solutions used for vertical fracture can be introduced to handle the issue of horizontal well with pressure drop along 


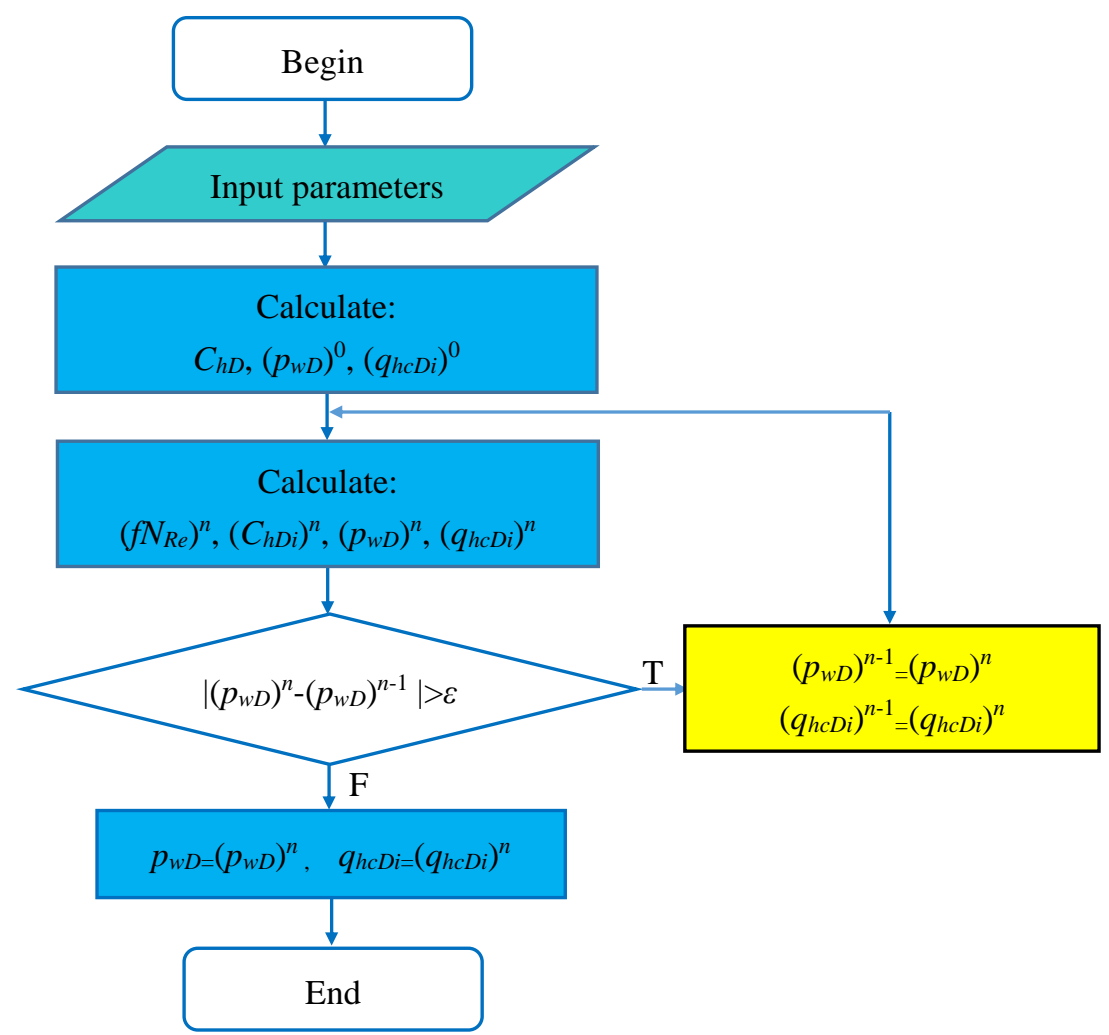

Fig. 2. Algorithm for computation of horizontal-well pressure.

Where:

$$
\bar{p}_{h D i}=\sum_{j=1}^{N} \bar{q}_{h D i} \cdot s \bar{p}_{u D i j}
$$

$\bar{p}_{u D}$ is the uniform-flux pressure solution for horizontal well.

As stated in Eqs. (19) and (20), there are N+1 unknown variables with $\mathrm{N}+1$ equations. Thus, Eq. (19) can be solved by Gauss elimination method.

\subsection{Iterative procedure}

Note that the variable $\xi_{D}$ in Eq. (16) is a function of the variable $x_{D}$ and depends on the distribution of conductivity $C_{h D}\left(x_{D}\right)$. According to our dimensionless definitions, $C_{h D}\left(x_{D}\right)$ varies with the value of $q_{h c}(x)$. However, the value of $q_{h c}(x)$ is unknown. Thus, at each time step, an iterative procedure is repeated until the wellbore pressure convergence is achieved.

$$
C_{h D}\left(x_{D}, \bar{q}_{h c D}^{k}\right) \cdot \frac{d \bar{p}_{h D}}{d x_{D}}=-2 \pi \cdot \bar{q}_{h c D}^{k+1}
$$

The algorithm for computation of horizontal-well pressure is presented in Fig. 2. The detailed procedures are illustrated as follows:

Step 1: Model inputs: reservoir parameters, horizontal well parameters.
Step 2: $k=0$ : calculating $C_{h D}$ (Eq. (9)) and solving Eq. (19) obtaining the initial pressure at heel $\left(p_{w D}\right)^{0}$ and distributions of flow rate $\left(q_{h c D i}\right)^{0}$ along the wellbore.

Step 3: $k=1$ : calculating the $\left(f N_{R e}\right)^{1}$ with Eqs. (1) and (3) using $\left(q_{h c D i}\right)^{0}$ to obtain the distributions of $\left(f N_{R e}\right)^{1}$ along the wellbore. Calculating $C_{h D}(x)$ (Eq. (8)) and obtaining the spatially distribution of $\left(C_{h D i}\right)^{1}$; calculating $\left(\hat{C}_{h D}\right)^{1}$ (Eq. (17)) and solve Eq. (19) obtaining $\left(p_{w D}\right)^{1},\left(q_{h c D i}\right)^{1}$; setting the error, $\varepsilon$. If $\left|\left(p_{w D}\right)^{1}-\left(p_{w D}\right)^{0}\right|<\varepsilon$, end.

Step 4: $k=2$ : If $\left|\left(p_{w D}\right)^{1}-\left(p_{w D}\right)^{0}\right|>\varepsilon$, repeating Step 3 . Using $\left(q_{h c D i}\right)^{1}$ to calculate $\left(C_{h D i}\right)^{2},\left(\hat{C}_{h D}\right)^{2},\left(p_{w D}\right)^{2},\left(q_{h c D i}\right)^{2}$. If $\left|\left(p_{w D}\right)^{2}-\left(p_{w D}\right)^{1}\right|<\varepsilon$, end. If $\left|\left(p_{w D}\right)^{2}-\left(p_{w D}\right)^{1}\right|>\varepsilon$, repeating Step 3.

...

Step M: $k=\mathrm{N}$ : If $\left|\left(p_{w D}\right)^{N}-\left(p_{w D}\right)^{N-1}\right|>\varepsilon$, repeating Step 3. Using $\left(q_{h c D i}\right)^{N}$ to calculate $\left(C_{h D i}\right)^{N},\left(\hat{C}_{h D}\right)^{N},\left(p_{w D}\right)^{N}$, $\left(q_{h c D i}\right)^{N}$. When $\left|\left(p_{w D}\right)^{N}-\left(p_{w D}\right)^{N-1}\right|<\varepsilon$, end.

\section{Validations}

\subsection{Pressure solutions without Wellbore Storage and Skin Factor}

To validate the new algorithm, the transient pressure solutions obtained in this study are compared with results reported in the literature (Ozkan et al., 1989, 1995). The comparisons are presented in Figs. 3 and 4.

As shown in Fig. 3, the variable of interest is the dimen- 


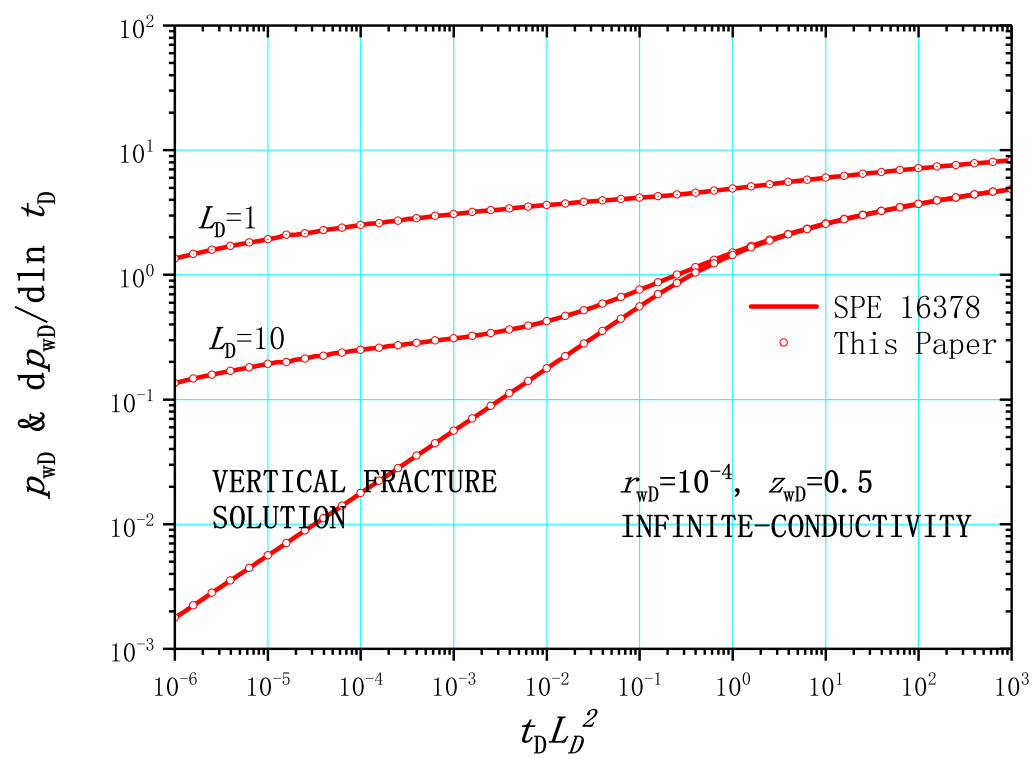

Fig. 3. Comparisons of transient pressure solutions from the new method with solutions from Ozkan et al. (1989) (SPE16378, Fig. 2).

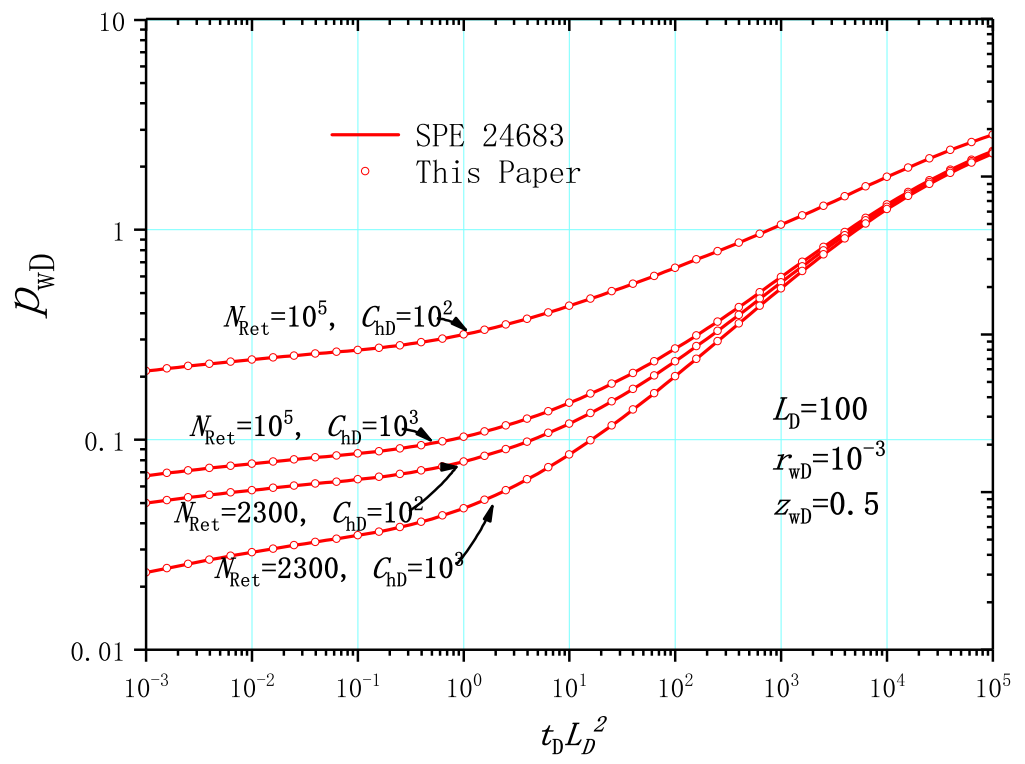

Fig. 4. Results comparison $\left(r_{w D}=r_{w} / h\right)$ (SPE24683, Fig. 9) (Laminar flow and turbulent flow in horizontal wellbores).

sionless horizontal-well length, $L_{D}=1$ and 10 , respectively. The well locates at the reservoir mid-height $\left(z_{w D}=0.5\right)$ and $r_{w D}=10^{-4}$. The bottom curve in Fig. 3 is the response of a fully penetrating vertically fractured well. Fig. 3 shows that the $L_{D} \geq 10$ solutions are indistinguishable from the vertically fractured well solution (on log-log coordinates) for $t_{D} \geq 1$. That is, the pressure response of long horizontal wells are almost identical to the responses for vertically fractured wells at long times, which is coincidence with Ozkan et al.'s views.

Fig. 4 shows that the effect of $N_{R e}$ and $C_{h D}$ on the pressure responses. By comparing the results with the presented literatures Ozkan et al. (1995), the new model is also verified. The solutions agree very well with those reported in the literature by Ozkan et al. (1995).

\subsection{Pressure solutions with Wellbore Storage and} Skin Factor

Since our semi-analytical solution is developed in Laplace space, the solution accounting for wellbore storage effect can be easily incorporated as following equation:

$$
\bar{p}_{w D}=\frac{s \bar{p}_{\text {owD }}}{1+C_{D} s^{2} \bar{p}_{\text {ow } D}}=\frac{s \bar{p}_{\text {owD }}}{1+s C_{D} \cdot s \bar{p}_{\text {owD }}}
$$

With skin factor considered, the continuity condition of 


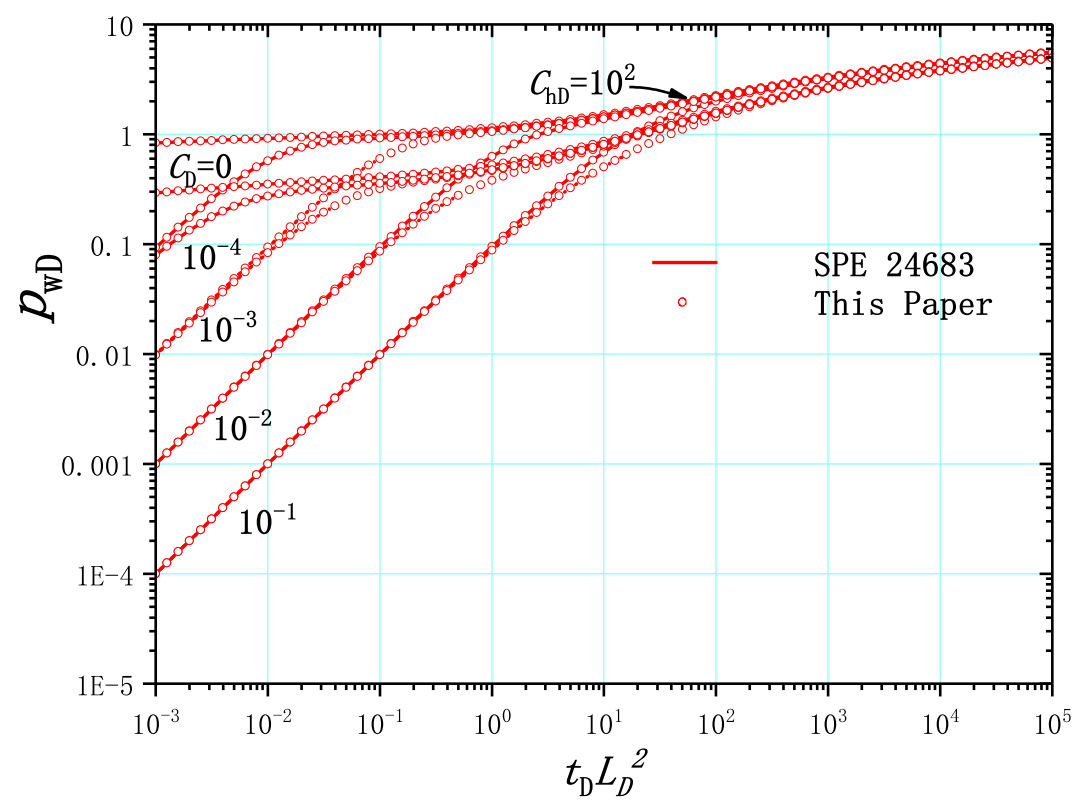

Fig. 5. The effect of wellbore storage and skin.

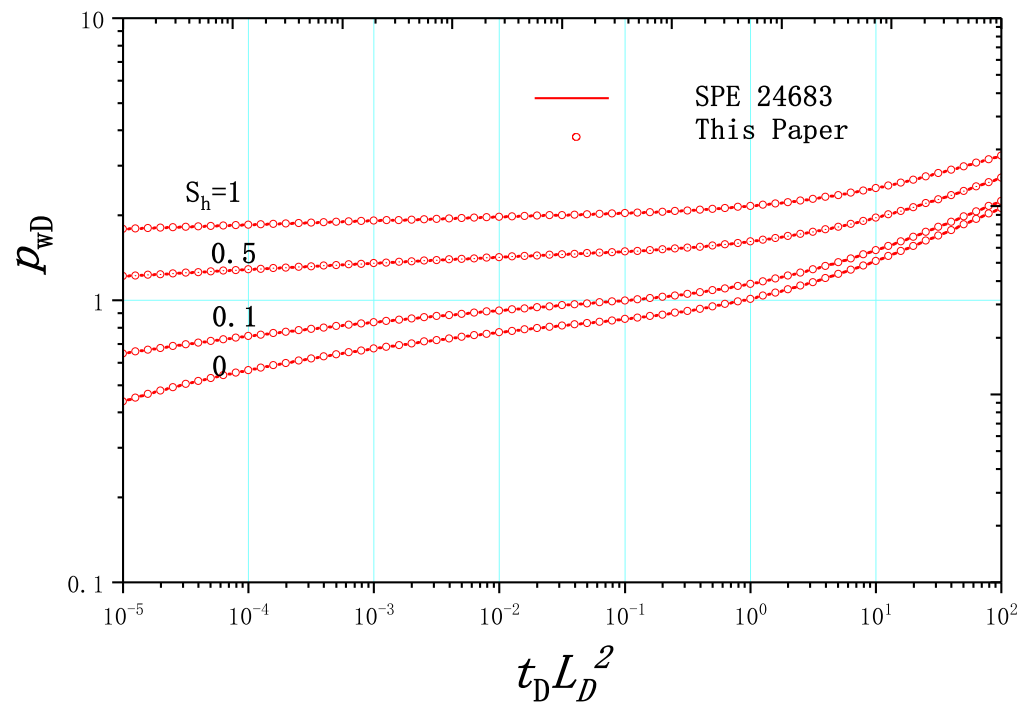

Fig. 6. Results comparison of the influence of skin effect $\left(C_{D}=0\right)$.

pressure on the surface of horizontal wellbore yields:

$$
p_{h D i}=p_{D i}+q_{h D i} \cdot S_{h i}, i=1,2, \cdots, N
$$

In Figs. 5 and 6, we present the transient pressure response under different skin factor.

\section{Conclusions}

In conclusion, the objective of this study is to develop a stable and robust algorithm in Laplace domain to analyze horizontal-well pressure response with pressure drop along the wellbore due to surface roughness. Detailed considerations of computational issues are an important contribution of this work.

Two new variables, i.e., horizontal-well permeability and conductivity, have been defined. Different from the definitions by Ozkan et al. (1989, 1995), the variables are not constant but changing spatially. By the utility of the new definitions, the solution equation is analogous to finite conductivity vertically fractured well.

Based on our study, the fluid flow along a horizontal well with pressure drop can be expressed as a varying-conductivity horizontal-well model which has the same form as the varyingconductivity fracture. A new dimension transformation has been used to change the varying-conductivity model into a constant-conductivity model, and then an iterative procedure 
has been introduced to obtain the pressure. Basically, this algorithm eliminates the need for computations in the real time domain.

\section{Nomenclature}

$$
\begin{aligned}
& A_{c}=\text { cross-sectional area, } \mathrm{ft}^{2} \\
& B=\text { volume factor, } \mathrm{RB} / \mathrm{STB} \\
& c=\text { fluid compressibility, } \mathrm{psi}^{-1} \\
& C_{D}=\text { dimensionless wellbore storage coefficient } \\
& C_{E}=\text { constant coefficient, dimensionless }
\end{aligned}
$$$$
C_{h D}(x)=\text { dimensionless horizontal-well conductivity at }
$$

$\hat{C}_{h D}=$ dimensionless horizontal-well conductivity after transformation

$C_{R e}=$ coefficient, dimensionless

$c_{t}=$ total compressibility, $\mathrm{psi}^{-1}$

$d=$ wellbore diameter, $\mathrm{ft}$

$f=$ fanning friction factor

$h=$ net pay, $\mathrm{ft}$

$k=$ permeability of drainage area, md

$k_{h}(x)=$ horizontal-well permeability at point $x$, md

$k_{w}=$ equivalent horizontal well permeability, md

$k_{y}=$ vertical rerservoir permeability, md

$L_{h}=$ length of horizontal well, $\mathrm{ft}$

$L_{r e f}=$ reference length, $\mathrm{ft}$

$N_{R e}(x)=$ Reynolds number at point $x$

$p=$ pressure, $\mathrm{psi}$

$p_{i}=$ initial formation pressure, $\mathrm{psi}$

$p_{h}=$ pressure in the horizontal well, psi

$p_{w}=$ wellbore pressure without strorage effect, psi

$q=$ production rate, $\mathrm{stb} /$ day

$q_{h c}=$ cumulative flux in cross-sectional area, stb/day

$q_{h c D}=$ dimensionless cumulative flux in cross-sectional area

$\tilde{q}_{h}=$ flow rate of per unit length from formation, i.e., flow rate strength, stb/d/ft

$q_{h D i}=$ dimensionless flow rate of the $i$-th segment

$r_{w}=$ wellbore radius, $\mathrm{ft}$

$s=$ Laplace transformation variable, dimensionless

$S_{h}=$ skin factor, dimensionless

$t=$ production time, day

$x=$ coordinate in the $x$ direction, $\mathrm{ft}$

$x_{w}=$ dimensionless wellbore coordinate in the $x$ direction

$x_{f}=$ fracture half length, $\mathrm{ft}$

$y=$ coordinate in the $y$ direction, $\mathrm{ft}$

$y_{w}=$ dimensionless wellbore coordinate in the $y$ direction

$z=$ coordinate in the $z$ direction, $\mathrm{ft}$

$z_{w}=$ well location in the vertical interval, $\mathrm{ft}$

$\xi_{D}=$ spatial variable after transformation

$\varepsilon=$ surface roughness, $\mathrm{ft}$

$\varphi=$ porosity, fraction

$\rho=$ density of reservoir fluid, $\mathrm{lbm} / \mathrm{ft}^{3}$

$\mu=$ fluid viscosity, $\mathrm{cp}$

\section{Subscripts}

$D=$ Dimensionless

$$
\begin{aligned}
& h=\text { horizontal-well property } \\
& i=\text { initial or segment } i \\
& j=\text { initial or segment } j \\
& t=\text { total } \\
& w=\text { wellbore property } \\
& v=\text { vertical }
\end{aligned}
$$

\section{Acknowledgments}

The authors would like to thank the sponsors of the National Natural Science Foundation of China (Grant No. 51674227) and the Fundamental Research Funds for the Central Universities (Grant No. 2-9-2015-133).

Open Access This article is distributed under the terms and conditions of the Creative Commons Attribution (CC BY-NC-ND) license, which permits unrestricted use, distribution, and reproduction in any medium, provided the original work is properly cited.

\section{References}

Abbasy, I., Ritchie, B., Pitts, M.J., et al. Challenges in completing long horizontal wells selectively. Paper SPE 116541 Presented at the SPE Asia Pacific oil \& gas conference and exhibition in Perth, Australia, 20-22 October, 2008.

Adesina, F.A.S., Churchill, A., Olugbenga, F. Modeling productivity index for long horizontal well. J. Energy Resour. Technol. 2007, 133(3): 033101.

Al-Haddad, S.M., Crafton, J.W. Productivity of horizontal wells. Paper SPE 21868 Presented at the Rocky Mountain Regional Meeting and Low-Permeability Reservoirs in Denver, Colorado, 15-17 April, 1991.

Babu, D.K., Odeh, A.S. Productivity of a horizontal well. SPE Reserv. Eng. 1989, 4(4): 417-421.

Britt, L.K., Jones, J.R., Miller, W.K. Defining horizontal well objectives in tight and unconventional gas reservoirs. Paper SPE 137839 Presented at the Canadian unconventional resources \& international petroleum conference in Calgary, Alberta, Canada, 19-21 October, 2010.

Chen, Z., Liao, X., Zhao, X., et al. A finite horizontal-wellconductivity model for pressure transient analysis in multiple fractured horizontal wells. Paper SPE 177230 presented in Proceedings of the SPE Latin American and Caribbean Petroleum Engineering Conference, Quito, Ecuador, 18-20 November, 2015.

Cho, H. Integrated optimization on a long horizontal well length. SPE Reserv. Eval. Eng. 2003, 6(2): 81-88.

Clonts, M.D., Ramey, H.J. Pressure transient analysis for wells with horizontal drainholes. Paper SPE 15116 Presented at the SPE California Regional Meeting, Oakland, California, 2-4 April, 1986.

Colebrook, C.F., Blench, T., Chatley, H., et al. Correspondence. Turbulent flow in pipes, with particular reference to the transition region between the smooth and Rough pipe Laws. (Includes plates). J. Inst. Civ. Eng. 1939, 12(8): 393-422.

Daviau, F., Mouronval, G., Bourdarot, G., et al. Pressure analysis for horizontal wells. Paper SPE 14251 Presented at the SPE Annual Technical Conference and Exhibition, 
Las Vegas, Nevada, 22-25 September, 1985.

Dikken, B.J. Pressure drop in horizontal wells and its effect on production performance. J. Pet. Technol. 1990, 42(11): 1426-1433.

Giger, F.M., Reiss, L.H., Jourdan, A.P. The reservoir engineering aspects of horizontal drilling. Paper SPE 13024 Presented at the SPE Annual Technical Conference and Exhibition, Houston, 16-19 September, 1984.

Goode, P.A., Kuchuk, F.J. Inflow performance of horizontal wells. SPE Reserv. Eng. 1991, 6(3): 319-323.

Goode, P.A., Thambynayagam, R.K. Pressure drawdown and buildup analysis of horizontal wells in anisotropic media. SPE Form. Eval. 1987, 2(4): 683-697.

Hill, A.D., Zhu, D. The relative importance of wellbore pressure drop and formation damage in horizontal wells. Paper SPE 100207 Presented at the SPE Europec/EAGE Annual Conference and Exhibition in Vienna, Austria, 12-15 June, 2006.

Joshi, S.D. Production forecasting methods for horizontal wells. Paper SPE17580 Presented at the SPE international meeting on petroleum engineering in Tianjin, China, 1-4 November, 1988.

Kuchuk, F.J. Well testing and interpretation for horizontal wells. J. Pet. Sci. Eng. 1995, 47(1): 36-41.

Kuchuk, F.J., Goode, P.A., Wilkinson, D.J., et al. Pressuretransient behavior of horizontal wells with and without gas cap or aquifer. SPE Form. Eval. 1991, 6(1): 86-94.

Li, X., Liang, J., Xu, W., et al. The new method on gaswater two phase steady-state productivity of fractured horizontal well in tight gas reservoir. Adv. Geo-Energy Res. 2017, 1(2): 105-111.

Liu, S., Tang, S., Yin, S. Coalbed methane recovery from multilateral horizontal wells in Southern Qinshui Basin. Adv. Geo-Energy Res. 2018, 2(1): 34-42.

Luo, W., Tang, C. A semianalytical solution of a vertical fractured well with varying vonductivity under non-darcyflow condition. SPE J. 2015, 20(5): 1028-1040.

Luo, W., Tang, C., Feng, Y. A semianalytical model for horizontal-well productivity with pressure drop along the wellbore. SPE J. 2018a.

Luo, W., Tang, C., Feng, Y., et al. Mechanism of fluid flow along a dynamic conductivity fracture with pressuredependent permeability under constant wellbore pressure. J. Pet. Sci. Eng. 2018c, 166: 465-475.
Luo, W., Tang, C., Wang, X. Pressure transient analysis of a horizontal well intercepted by multiple non-planar vertical fractures. J. Pet. Sci. Eng. 2014, 124: 232-242.

Luo, W., Tang, C., Zhou, Y., et al. A new semi-analytical method for calculating well productivity near discrete fractures. J. Nat. Gas Sci. Eng. 2018b, 57: 216-223.

Mutalik, P.N., Godbole, S.P., Joshi, S.D. Effect of drainage area shapes on the productivity of horizontal wells. Paper SPE 18301 presented at the SPE 63rd Annual Technical Conference, Houston, 25 October, 1988.

Novy, R.A. Pressure drops in horizontal wells: When can they be ignored? SPE Reserv. Eng. 1995, 10(1): 29-35.

Ozkan, E., Raghavan, R. New solutions for well-test analysis problems. Part 1: Analytical considerations. SPE Form. Eval. 1991, 6(3): 359-368.

Ozkan, E., Raghavan, R., Joshi, S.D. Horizontal well pressure analysis. SPE Form. Eval. 1989, 4(4): 567-575.

Ozkan, E., Sarica, C., Haciislamoglu, M., et al. Effect of conductivity on horizontal well pressure behavior. SPE Adv. Technol. Ser. 1995, 3(1): 85-94.

Ozkan, E., Sarica, C., Haciislamoglu, M. Influence of pressure drop along the wellbore on horizontal-well productivity. SPE J. 1999, 4(3): 288-301.

Sarica, C., Haciislamoglu, M., Raghavan, R., et al. Influence of wellbore Hydraulics on pressure behavior and productivity of horizontal gas wells. J. Cell Biol. 1994, 210(7): 1257-1268.

Wang, W., Zheng, D., Sheng, G., et al. A review of stimulated reservoir volume characterization for multiple fractured horizontal well in unconventional reservoirs. Adv. GeoEnergy Res. 2017, 1(1): 54-63.

Wang, X., Economides, M.J. Horizontal well deliverability with turbulence effects. Paper SPE 121382 Presented at the SPE European Formation Damage Conference in Scheveningen, The Netherlands, 27-29 May, 2009.

Wang, X., Luo, W., Hou, X., et al. Pressure transient analysis of multi-stage fractured horizontal wells in boxed reservoirs. Pet. Explor. Dev. 2014, 41(1): 82-87.

Yue, P., Du, Z., Chen, X., et al. The pressure drop model of liquid flow with wall mass transfer in horizontal wellbore with perforated completion. Math. Probl. Eng. 2014, (1): $1-8$. 


\section{Appendix A: Dimensionless definitions of variables}

For the sake of simplicity, we will present our solution in terms of the following dimensionless variables. The dimensionless reservoir pressure $p_{D}$, dimensionless wellbore pressure $p_{w D}$ and the horizontal-well pressure $p_{h D}$, are given, respectively, by:

$$
\begin{gathered}
p_{D}=\frac{k h\left(p_{i}-p\right)}{141.2 \mu B q}, \\
p_{w D}=\frac{k h\left(p_{i}-p_{w}\right)}{141.2 \mu B q}, \\
p_{h D}=\frac{k h\left(p_{i}-p_{h}\right)}{141.2 \mu B q}
\end{gathered}
$$

The dimensionless time is:

$$
t_{D}=\frac{2.637 \times 10^{-4} k t}{\phi \mu c_{t} L_{r e f}^{2}}
$$

The dimensionless distances $x_{D}, y_{D}, z_{w D}, L_{D}$ and $r_{w D}$ are defined, respectively, by:

$$
\begin{gathered}
x_{D}=\frac{x}{L_{r e f}} \\
y_{D}=\frac{y}{L_{r e f}} \\
z_{w D}=\frac{z_{w}}{h} \\
L_{D}=\frac{L_{h}}{2 h} \sqrt{\frac{k_{v}}{k}} \\
r_{w D}=\frac{r_{w}}{2 h}\left[\left(\frac{k}{k_{v}}\right)^{1 / 4}+\left(\frac{k_{v}}{k}\right)^{1 / 4}\right]
\end{gathered}
$$

The relative well surface roughness is:

$$
\varepsilon_{D}=\frac{\varepsilon}{2 r_{w}}
$$

The dimensionless rate strength $\tilde{q}_{h D}$, dimensionless rate $q_{h D}$ and dimensionless cross-sectional rate $q_{h c D}$ are defined as:

$$
\begin{gathered}
\tilde{q}_{h D}=\frac{\tilde{q}_{h} L_{r e f}}{q}, \\
q_{h D}=\frac{q_{h}}{q}, \\
q_{h c D}=\frac{q_{h c}}{q}=\int_{x}^{L_{h}} \frac{q_{h}\left(x^{\prime}, t\right) d x^{\prime}}{q}
\end{gathered}
$$

In this paper, we define the reference length $L_{r e f}$ as:

$$
L_{r} e f=\frac{L_{h}}{2}
$$




\section{Appendix B: Discretization model of horizontal well with varying conductivity}

The fluid flow along the horizontal well can be regarded as a varying-conductivity behavior. With respect to the assumption of varying conductivities being a function of location, the conductivity of each segment is different $\left(C_{h D 1}, C_{h D 2}, \cdots, C_{h D N}\right)$.

Based on our transformation method, the discretization model with equal length $(\Delta x)$ and varying conductivities can be changed into the model with unequal length $\left(\Delta \xi_{D i}\right)$ and constant conductivities (Luo and Tang, 2015). It is assumed that the flow rate for each segment is uniformly distributed. The cumulative flux distribution with the horizontal well, $q_{h c D}$, varies from point along the horizontal well. The flux distribution, $q_{h c D}$, can be approximated at point $\xi_{D}$ as follows:

$$
\begin{gathered}
q_{h c D}\left(\xi_{D}\right)=q_{h c D i-1 / 2}+\frac{q_{h c D i+1 / 2}-q_{h c D i-1 / 2}}{\Delta \xi_{D i}}\left(\xi_{D}-\xi_{D i-1 / 2}\right), \\
\xi_{D i-1 / 2}<\xi_{D}<\xi_{D i+1 / 2}
\end{gathered}
$$

The flow rate of the segment $i$ can be written as:

$$
q_{h D i}=q_{h c D i-1 / 2}-q_{h c D i+1 / 2}
$$

Substituting Eq. (B-2) into Eq. (B-1) yields:

$$
\begin{gathered}
q_{h c D}\left(\xi_{D}\right)=q_{h c D i-1 / 2}-\frac{q_{h D i}}{\Delta \xi_{D i}}\left(\xi_{D}-\xi_{D i-1 / 2}\right), \\
\xi_{D i-1 / 2}<\xi_{D}<\xi_{D i+1 / 2}
\end{gathered}
$$

By integrating the horizontal-well flow equation (Eq. (18)) for $\xi_{D}$ between 0 to $\xi_{D i}$, we can obtain:

$$
-\int_{0}^{\xi_{D i}} \frac{\partial p_{h D}}{\partial \xi_{D}} d \xi_{D}=\left(\frac{2 \pi}{\hat{C}_{h D}}\right) \times \int_{0}^{\xi_{D i}} q_{h c D}\left(\xi_{D}\right) d \xi_{D}
$$

Evaluating Eq. (B-4) yields:

$$
p_{h D}(0)-p_{h D}\left(\xi_{D i}\right)=\left(\frac{2 \pi}{\hat{C}_{h D}}\right) \cdot \int_{0}^{\xi_{D i}} q_{h c D}\left(\xi_{D}\right) d \xi_{D}=\left(\frac{2 \pi}{\hat{C}_{h D}}\right) \cdot I\left(\xi_{D i}\right)
$$

In this manner, a linear cumulative flux distribution is assumed that is a good approximation for large values of $N$. For a horizontal-well system, $q_{h c D}$ varies from one at the wellbore to zero at the tip of the horizontal well. From Eq. (B-5), the integrals can be evaluated separately, as follows:

$$
\begin{aligned}
I\left(\xi_{D i}\right) & =\int_{0}^{\xi_{D i}} q_{h c D}\left(\xi_{D}\right) d \xi_{D} \\
& =\int_{0}^{\xi_{D i-1 / 2}} q_{h c D}\left(\xi_{D}\right) d \xi_{D}+\int_{\xi_{D i-1 / 2}}^{\xi_{D i}} q_{h c D}\left(\xi_{D}\right) d \xi_{D} \\
& =\int_{\xi_{D 1-1 / 2}}^{\xi_{D 1+1 / 2}} q_{h c D}\left(\xi_{D}\right) d \xi_{D}+\int_{\xi_{D 2-1 / 2}}^{\xi_{D 2+1 / 2}} q_{h c D}\left(\xi_{D}\right) d \xi_{D}+\cdots+\int_{\xi_{D i-1-1 / 2}}^{\xi_{D i-1+1 / 2}} q_{h c D}\left(\xi_{D}\right) d \xi_{D}+\int_{\xi_{D i-1 / 2}}^{\xi_{D i}} q_{h c D}\left(\xi_{D}\right) d \xi_{D}
\end{aligned}
$$

Note that:

$$
q_{h c D i-1 / 2}=\sum_{j=1}^{N} q_{h D j}-\sum_{j=1}^{i-1} q_{h D j}
$$

Substituting EqS. (B-7) and (B-3) into Eq. (B-6) and summing same term of $q_{h D i}$ :

$$
\begin{aligned}
I\left(\xi_{D i}\right)= & \xi_{D i} \cdot \sum_{j=1}^{N} q_{h D j}-\left[\sum_{j=1}^{i-1}\left(\xi_{D i}-\sum_{n=1}^{j} \Delta \xi_{D n}\right) \cdot q_{h D j}\right] \\
& -\left(\frac{\Delta \xi_{D 1}}{2} \cdot q_{h D 1}+\cdots+\frac{\Delta \xi_{D i-1}}{2} \cdot q_{h D i-1}+\frac{\left(\xi_{D i}-\xi_{D i-1 / 2}\right)^{2}}{2 \cdot \Delta \xi_{D i}} \cdot q_{h D i}\right)
\end{aligned}
$$


Using the wellbore condition:

$$
\begin{aligned}
& p_{w D}=p_{h D}(0), \\
& \sum_{j=1}^{N} q_{h D j}=1
\end{aligned}
$$

Finally, the discretized form of Eq. (B-5) can be written as:

$$
p_{w D}-p_{h D i}=\left(\frac{2 \pi}{\hat{C}_{h D}}\right) \cdot\left[\xi_{D i} \cdot \sum_{j=1}^{N} q_{h D j}-\frac{\left(\xi_{D i}-\xi_{D i-1 / 2}\right)^{2}}{2 \cdot \Delta \xi_{D i}} \cdot q_{h D i}-\sum_{j=1}^{i-1}\left(\frac{\Delta \xi_{D j}}{2}+\xi_{D i}-\sum_{n=1}^{j} \Delta \xi_{D n}\right) \cdot q_{h D j}\right]
$$

